\title{
Role of Reducing the Vulnerability of Urban Texture in the Capacity of Relief and Rescue Operation after a Possible Earthquake in the District 5 of Isfahan, Iran
}

\author{
Seyed Arash Hosseini Sabzevari ${ }^{1} \mathbb{D}$, Atoosa Hassani ${ }^{2} \mathbb{D}$ \\ Date of submission: 28 Nov. 2020 Date of acceptance: 3 Mar. 2021
}

\section{Original Article}

\begin{abstract}
INTRODUCTION: Despite the progress of urbanization, earthquake as one of the most important natural hazards threatens most cities in the world. Accordingly, managing and reducing the vulnerability of cities to this disaster, as well as the planned relief and rescue operation, are of particular importance. The city of Isfahan, Iran, is one of the areas which requires proper attention and planning due to its high population density and vulnerability. In this regard, this study was conducted to identify the physical texture vulnerability of the District 5 of Isfahan to earthquakes and its impact during rescue and relief operations.
\end{abstract}

METHODS: To conduct the research, the indices of access to green space, building density, population density, distance from the fault, distance from relief centers, access to roads and arteries, and width of roads were selected due to their frequency in studies conducted on the vulnerability of cities and scores given by specialists. Finally, the critical areas of the region were determined by weighting each of the indices using the analytic hierarchy process method in Expert Choice software (version 11) and examining the vulnerability of the region in the Geographic Information System.

FINDINGS: It was revealed that $68 \%$ of the area had a suitable density of green space, and $73 \%$ and $88 \%$ of the region had low building and population densities, respectively. Moreover, $76 \%$ of the area had good access to relief centers and the whole area had proper passages. Finally, it was found that no faults passed through this area, and the impact of adjacent faults caused this area to be in a moderate situation in terms of vulnerability.

CONCLUSION: The critical areas were determined by overlaying each of the vulnerability layers of the city and applying their degree of importance. The results showed that $6 \%$ and $18 \%$ of the areas were in critical and highly vulnerable conditions, respectively. Therefore, rescue and relief operations would be performed with an acceptable capacity after such disasters as earthquakes.

Keywords: AHP; District 5 of Isfahan; Earthquake; GIS; Rescue; Vulnerability

How to cite this article: Hosseini Sabzevari A, Hassani A. Role of Reducing the Vulnerability of Urban Texture in the Capacity of Relief and Rescue Operation after a Possible Earthquake in the District 5 of Isfahan, Iran. Sci J Rescue Relief 2021; 13(1): 77-85.

\section{Introduction}

$\int$ arthquake is considered one of the most catastrophic natural disasters that can have devastating effects on a human's normal life and living process. Records show that more than one million earthquakes occur annually worldwide, equivalent to two earthquakes per minute (1). On the other hand, rapid urbanization, especially in developing countries, has led to the settlement of more than half of the world's population in cities (2). This issue makes the threat of earthquakes more likely to increase due to the increasing urbanization worldwide, which consequently, exposes millions of people to the dangers of this disaster (3). Earthquake casualties are approximately estimated at $60 \%$ of all deaths associated with other disasters (1).

Iran is an earthquake-prone country, both and the growing population of the country in recent decades and the increasing desire to migrate from rural to urban areas in the same period have led to rapid urban development (4). This has led to an

1-MSc Student of Post-Disaster Reconstruction, Shahid Beheshti University, Tehran, Iran

2-PhD Student of Architecture, Shahid Beheshti University, Tehran, Iran

Correspondence to: Atoosa Hassani, Email: atoosa_h70@yahoo.com 
increase in the risk of Iranian cities against disasters and hazards in recent years (5). The effects of an accident are more devastating in one place than in another one and depend on the components of the local vulnerability of the community (6).

Vulnerability reduction is considered a fundamental element of natural disaster risk management and is the most important prerequisite for the disaster resilience of cities. Therefore, to reduce the damage caused by disasters and increase the ability to respond to post-disaster properly, the investigation and evaluation of vulnerability against them are of particular importance. For this reason, timely and efficient management strategies and disaster risk management, with a correct understanding of the disaster itself, seems essential (6).

The city of Isfahan, Iran, is considered vulnerable due to population concentration, lack of a basic plan to deal with the future crisis, lack of proper preparedness of the government and people in the face of the earthquake crisis, non-observance of reinforcement laws and regulations, the existence of illegal structures in the form of informal settlements, unauthorized and unprincipled high-rises, the use of incompatible materials in the construction of recent years (especially in high-rise buildings), high groundwater levels and ground instability due to this phenomenon, citizens' relief from the absence of the earthquake and its extension to the future, and many other cases (7).

The important geographical and economical status of Isfahan Province in Iran, the emphasis of experts on the priority and necessity of conducting detailed studies on seismic risk zoning for cities located along faults, and directing population flows and other activities to low-risk and safe areas to reduce vulnerability reveals the need to determine the relative risk of earthquakes in Isfahan Province (8). Accordingly, this research aimed to assess the physical vulnerability of District 5 of Isfahan to a possible earthquake that can improve performance during rescue and relief operations the potential casualties and reduce the potential loss of life by using a proper planning and management platform. Therefore, in the present study, these questions are answered: 'What is the vulnerability of District 5 of Isfahan to a possible earthquake?' and 'What is the impact of the city's physical vulnerability on rescue and relief capacity?'

\section{Research background}

Ganjeie et al. examined important indicators in a study entitled "Determining effective indicators in determining rescue and relief evacuation routes in urban areas from the perspective of crisis management" and mentioned safety, traffic, and route length in this regard (9). Anari et al., in an article entitled "Analysis and evaluation of effective variables on improving the urban road network resilience in the natural and man-made crises (case study: five areas of the eastern part of Tehran)", evaluated the network of communication roads as the most important elements of the physical structure of the city in rescue and relief operations (10).

Eskandari and Arzegan, in a study entitled "A new model for location - routing - relief logistic inventory in earthquake situations under fuzzy conditions based on risk management (Case study: Tehran city)", reported about the importance of proper planning and disaster crisis management before the earthquake incidence and highlighted the issue of finding enough space to evacuate people, having the right paths to achieve quality rescue and relief, and reducing costs (11).

\section{Methods}

This applied research was conducted based on a descriptive-analytical design. The data collection was performed using various methods, including library research, presence in the study area, and observation. To identify the indicators used in the research and the degree of their importance, a questionnaire with a score of 0 to 5 was designed and distributed among the experts in the fields of urban design, urban planning, and post-traumatic reconstruction. The reason for using this method was to benefit from the comprehensive view of experts from different aspects.

To ensure the standardization and validity of the questionnaire, it was reviewed and approved by several experts. Moreover, the test-retest reliability method was used to evaluate the reliability of the questionnaire. In this method, to assess the reliability, test questions are given twice to a single group under the same conditions and the obtained scores are compared (12). The vulnerability layers of the region have been 
determined by weighting the indicators using the analytic hierarchy process (AHP) model and Geographic Information Systems maps. In the AHP method, pairwise comparison is used, which is known as the basis of the hierarchical process (13). This comparison was performed using the weights listed in Table 1.

In this method, initially, the studied indices are compared and the relative importance of each pair is entered and measured in a matrix according to the scores in the table above (1 to 9). Afterward, to calculate the weight of the indicators and the importance of the coefficient of each, the data are entered into the Expert Choice software (version 11). This measure determines the effect of each of the indicators on obtaining the critical map. The importance of this is related to the fact since each of the influential indicators does not affect the final result of the city's vulnerability to the same extent; it is possible to reach a more accurate result of the vulnerability by weighing them.

According to Figure 1, it is determined that the selected indicators of the research will affect which part of the rescue and relief stage and how they will determine the capacity of this stage. Figure 1 shows the population density, building density, and distance from the fault refer to the extent of the destruction, debris, and trapped human, which are effective in the rescue stage. Furthermore, the quality of transfer from the accident site to other centers or access to the accident site depends on the condition of the roads. Finally, distance from relief centers and green spaces affect the safe evacuation of the injured and survivors.

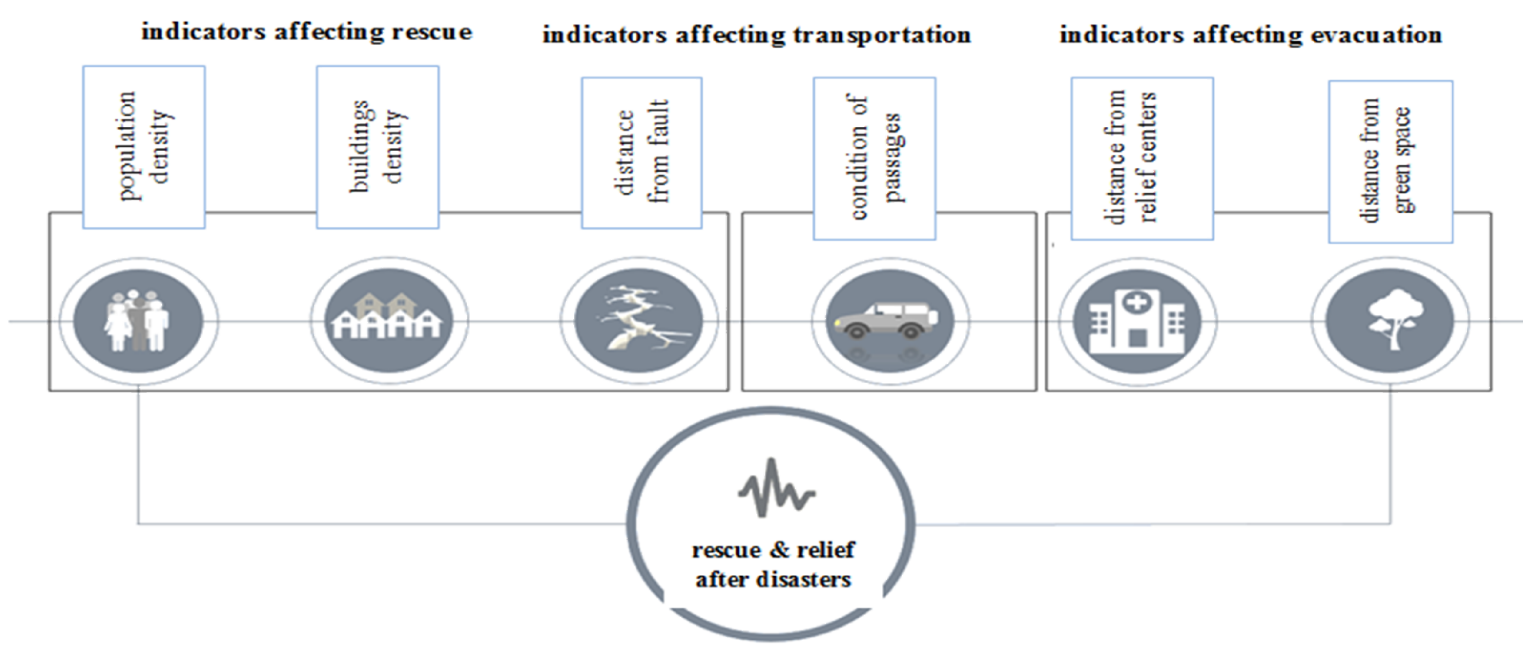

Figure 1. Indicators affecting the rescue and relief operation

\section{Study area}

District 5 of Isfahan, located in its southwest part, was selected as the study area. This region has 11 neighborhoods and according to the statistics, it had a population of 163,030 residents and 39,955 families in 2014. The region is 1,196 hectares wide, of which 69.75 hectares are in the worn-out texture. The most and least densely populated neighborhoods are Vahid and Sepahanshahr neighborhoods with 251 and 87 residents per hectare, respectively.

The widest and smallest neighborhoods in District 5 are Sepahanshahr and Sepahan with 412and 22-hectares areas, respectively. Since the population size and area of each zone are related to each other and to increase the population size, more surface area is needed, therefore, the balance between population and area shares of different urban areas can reduce urban and local problems, including traffic, congestion, and pollution and help increase the comfort and well-being of citizens.

Table 1. Thomas L. Saaty's binary comparison matrix (14)

\begin{tabular}{|c|c|}
\hline $\begin{array}{c}\text { Intensity of the } \\
\text { importance }\end{array}$ & Definition \\
\hline 1 & Equal importance \\
3 & Weak importance of one over another \\
5 & Essential or strong importance \\
7 & Demonstrated importance \\
9 & Absolute importance \\
\hline $2,4,6,8$ & $\begin{array}{c}\text { Intermediate values between the two } \\
\text { adjacent judgments }\end{array}$ \\
\hline
\end{tabular}




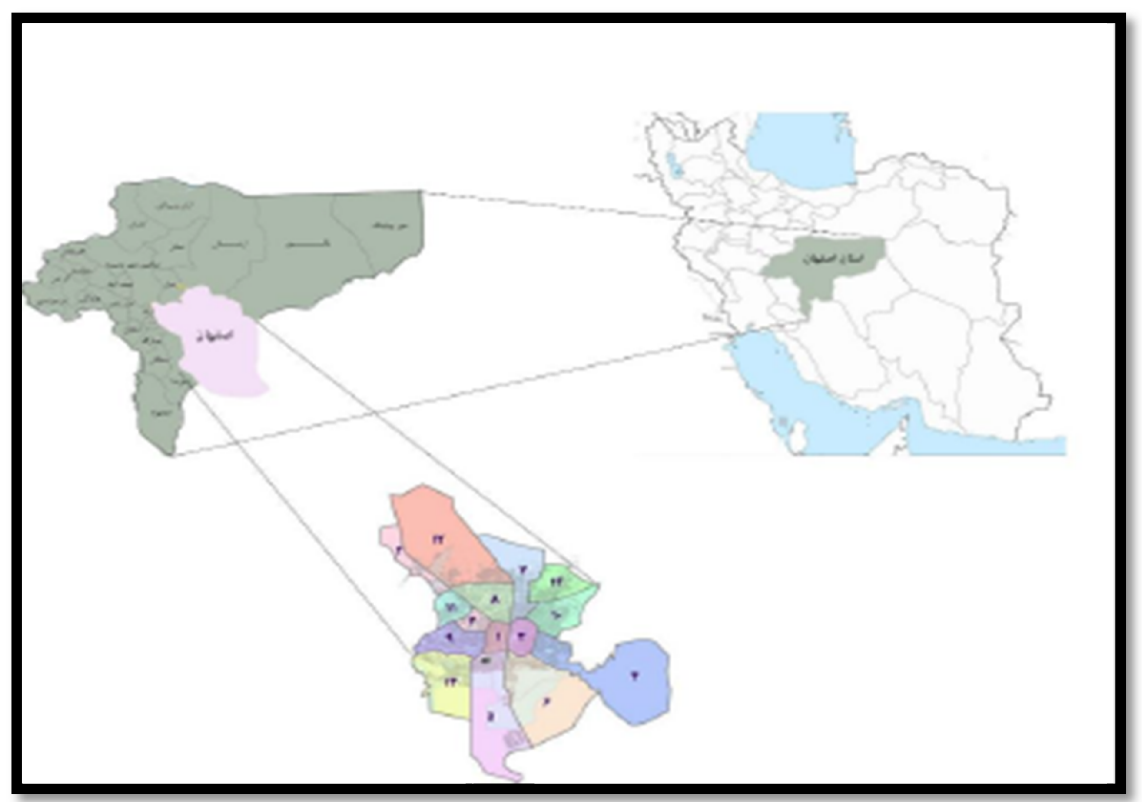

Figure 2. Location of district 5 of Isfahan

In this area of Isfahan, an imbalance is observed between the surface area and population, consequently, urban problems, such as congestion and traffic, are evident in this region. On the other hand, according to the provided statistics, 24\%$40 \%$ of the houses in this region have an area of less than $100 \mathrm{~m}^{2}$. Based on the same statistics, $5 \%$ $30 \%$ and less than $1 \%$ of the houses in this region have an area of less than $75 \mathrm{~m}^{2}$ and more than 300 $\mathrm{m}^{2}$, respectively. Therefore, most of the texture of the District 5 of Isfahan is of fine-grained fabric (15). In addition to the mentioned problems in this region, the existence of low-durable materials, old buildings, disordered pattern of the fabric, low width, confinement of passages, and high population density are among the problems that have emerged in the District 5 of Isfahan (16) (Figure 3).

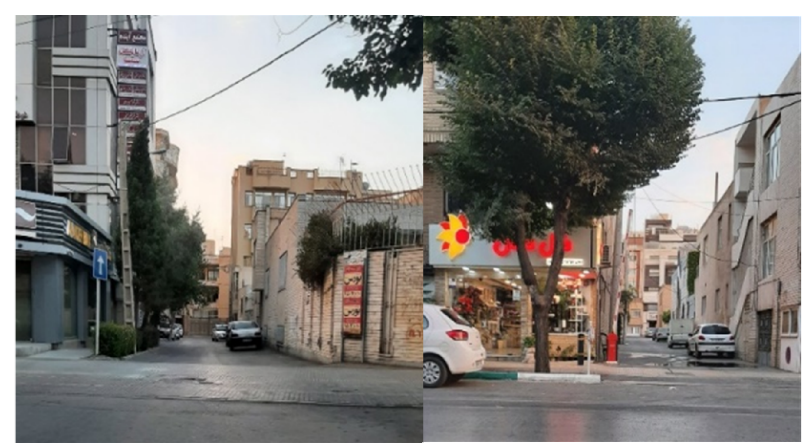

Figure 3. Condition of passages and worn-out texture in the area

\section{Findings}

\section{Vulnerability of District 5 of Isfahan}

To prepare the physical vulnerability layers of the region during rescue and relief operation, the following indicators were used: distance from the fault, access to green spaces, population and construction density, width of passages, access to passages with 5 degrees of vulnerability (very low, low, medium, high, and very high). These indicators show the capacity of the region in the response phase at an earthquake occurrence.

\section{Access to green spaces}

The presence of open spaces in cities and the usability of such spaces during an earthquake play important roles in reducing the damage and casualties caused by this disaster. These spaces can be used as open spaces for both initial evacuation and construction sites for temporary housing (17). In designing cities, it is necessary to avoid construction in high-risk areas and allocate them to green space (18). The density of green spaces was calculated to achieve the vulnerability of the region based on the index of access to these spaces (Figure 4).

The area of green space in the District 5 of Isfahan is calculated at about $1,071,934 \mathrm{~m}^{2}$, and a population of 163,030 people is living in this area. Considering the need of each person for about 2 $\mathrm{m}^{2}$ of open space after disasters (19), the residents 
of this area would need about $326,060 \mathrm{~m}^{2}$ of space after the earthquake. In this respect, it is determined that the area of green spaces in this region is sufficient to accommodate its population. The presence of areas with low green space density indicates the inappropriate distribution of such spaces in the region.

\section{Population and building density}

The low population density in the city due to the type of land parcels (building density) and the even distribution of this density throughout the city would decrease the vulnerability of the city to earthquakes. Conversely, high population density in the city means more casualties and damage during an earthquake incidence, leading to more death tolls due to the collapse of debris, closure of roads and passages, reduction of the possibility of escaping dangerous situations and accessing to safe areas, and difficulty of rescuing the injured because of the blocked roads (20). To prepare these maps, the density of population and buildings in this area was calculated (figures 5 and 6).

The results of studies show that this area is in a good position in terms of population and building density. Only some northern sections of this region are in a critical situation regarding building density.

\section{Distance from relief centers}

Access to medical centers and fire stations through communication networks accelerates rescue and relief operations and services to the injured. Consequently, distance from medical centers and fire stations increases the likelihood of vulnerability against an earthquake (21). To prepare this map, the distance of all parts of the region from the relief centers was calculated (Figure 7).

According to Figure 7, the vulnerability of the region considering the index of distance from relief centers is in a moderate to very good condition and only $5 \%$ of the area has a low density of relief centers.

\section{Passage index}

The dimensions (length and width) of the routes play important roles in evacuating and rescuing the injured (22). The importance of this issue is highlighted in times of fleeing, sheltering, evacuating, and providing relief since more survivors and injured can be transported by relief groups (23). In most earthquake-stroke areas, the number of casualties is not necessarily due to the earthquake itself, rather the main problem is related to the blockage of communication networks (24). Accordingly, wide paths should be replaced with narrow and winding alleys (25). To evaluate vulnerability with considering the access to the passages, the distance of all parts of the region from the passages and their width were calculated (figures 8 and 9).

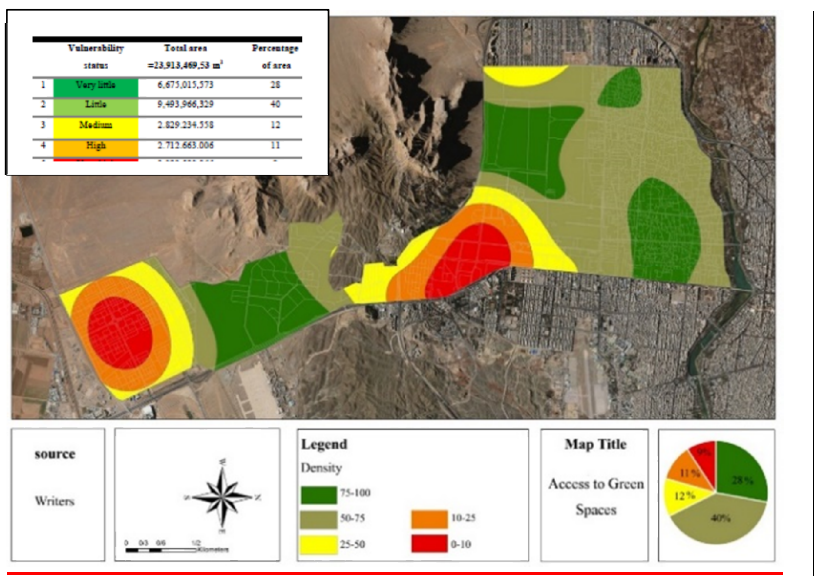

Figure 4. Access to Green spaces map of district 5 of Isfahan in GIS

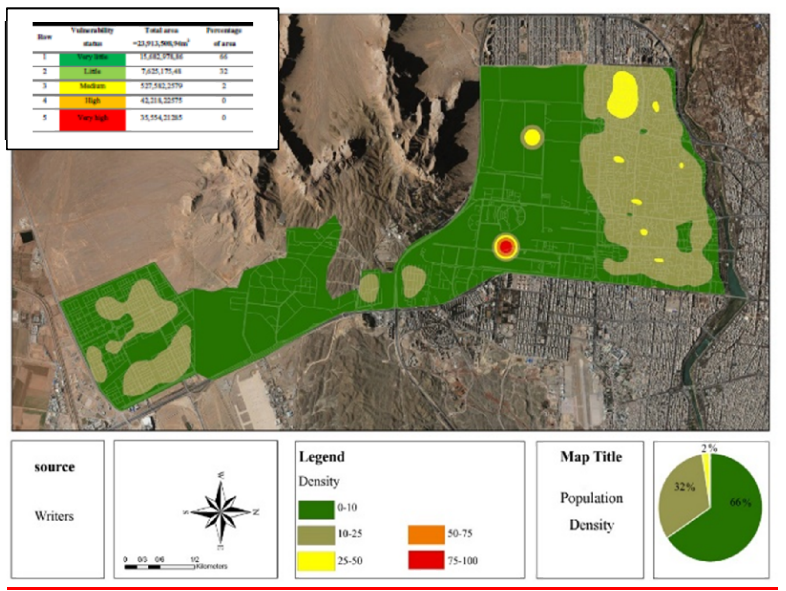

Figure 5. Population density map of district 5 of Isfahan in GIS

The obtained figures and maps show that District 5 of Isfahan is in a good condition in terms of access to roads and arteries, and the areas with high to very high vulnerabilities make up only $3 \%$ of this region.

\section{Distance from faults}

It is important to study faults that have seismic potential. The identification of active fault zones 
and estimation of the seismic potential of such faults can play prominent roles in reducing human and financial losses. There is a close relationship between fault and earthquake, indicating that greater distance from the fault decreases the vulnerability likelihood of that region (26). To prepare the vulnerability map of this region, the distance of all parts of the region to the faults was calculated (Figure 10).

Since no faults pass through this area, its vulnerability is completely at a moderate level.

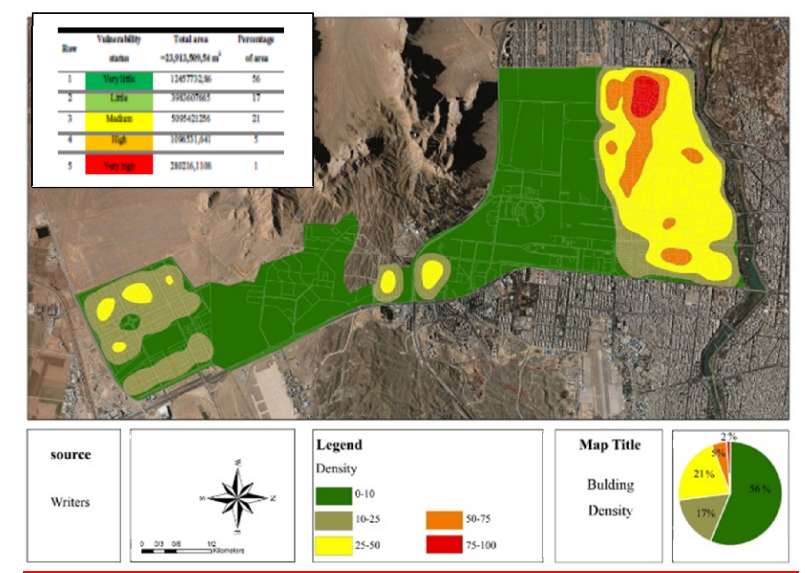

Figure 6. Building density map of district 5 of Isfahan in GIS

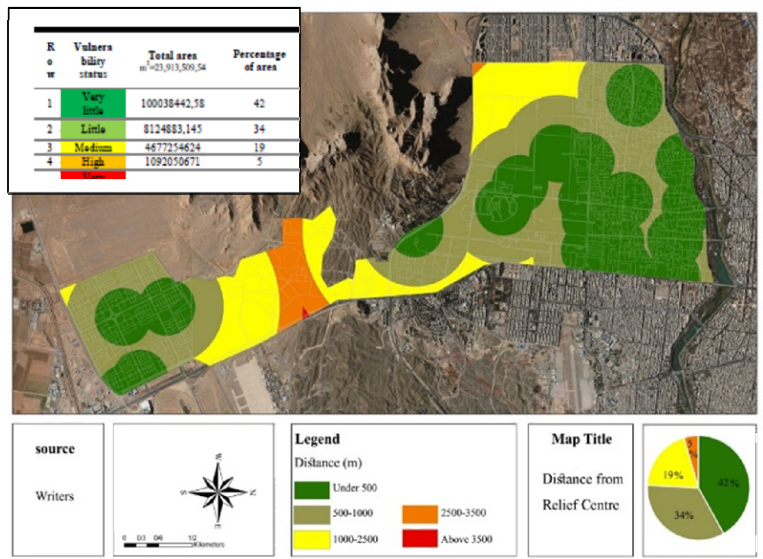

Figure 7. Distance from relief centers map of district 5 of Isfahan in GIS

\section{Critical area}

In order to overlay the vulnerability layers of the region in relation to the indices of access to green spaces, population density, building density, width of passages, access to arteries and passages, distance from the fault, it is required to determine the importance and impact level of each of them in preparing a critical map. To this end, their binary comparisons have been performed using the AHP method in Expert Choice software (version 11) (Figure 11).

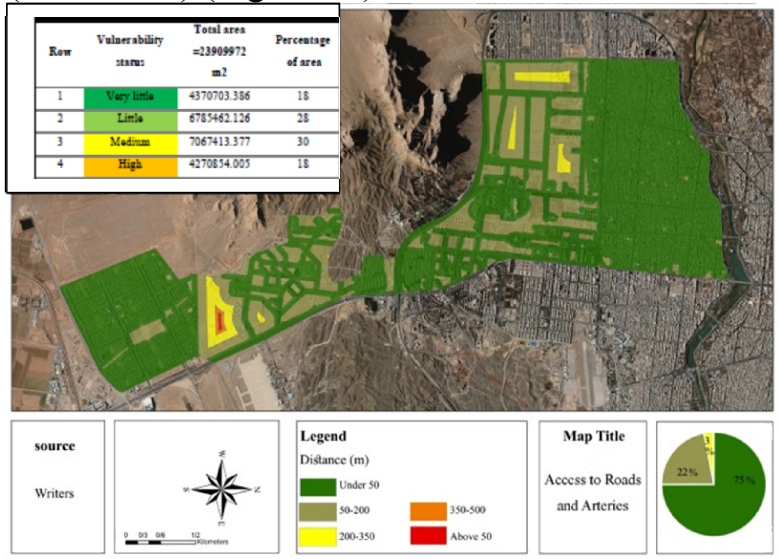

Figure 8. Distance from infrastructures and passages of district 5 of Isfahan in GIS

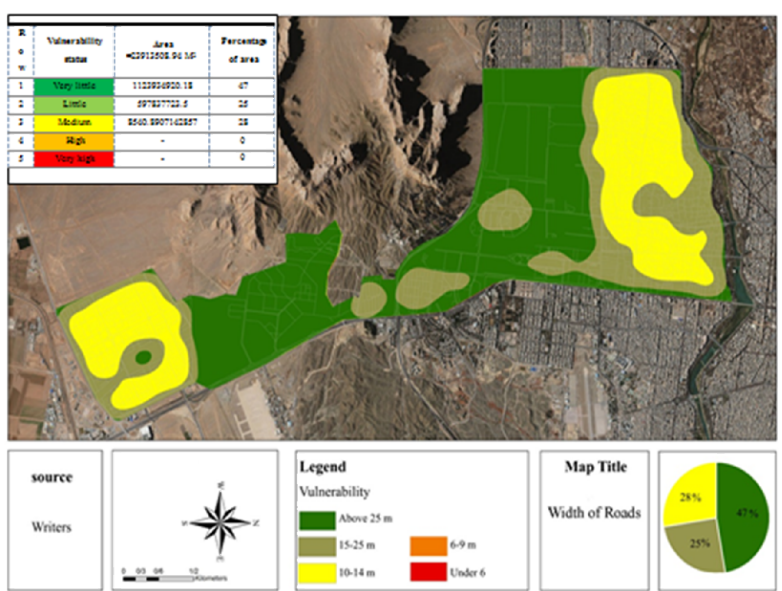

Figure 9. Width of passages/roads Map in district 5 of Isfahan in GIS

The map of critical areas was prepared by overlaying the layers with the specified coefficient of importance (Figure 12).

The findings of investigations reveal that the spread of physical vulnerability in the region is diverse and scattered in all parts of it. Figure 9 shows the five degrees of vulnerability in the region. Based on the results, only $24 \%$ of the area was high/very high vulnerable, while $30 \%$ and $46 \%$ of this region were located in moderate and very low/low vulnerable areas.

The results of the present study are consistent with those of research conducted by Fallahi and Hassani. According to the results of the mentioned study, Hashtgerd New City, Alborz Province, Iran, is considered one of the most vulnerable areas to earthquake due to its improper passages, high population and building density close to the city's 
faults, limited access to rescue and relief centers, and improper distribution of green spaces (27).

The findings of the current research are in line with those of a study performed by Khodadadi et al. in the field of urban texture vulnerability. According to their findings, Karaj metropolis,

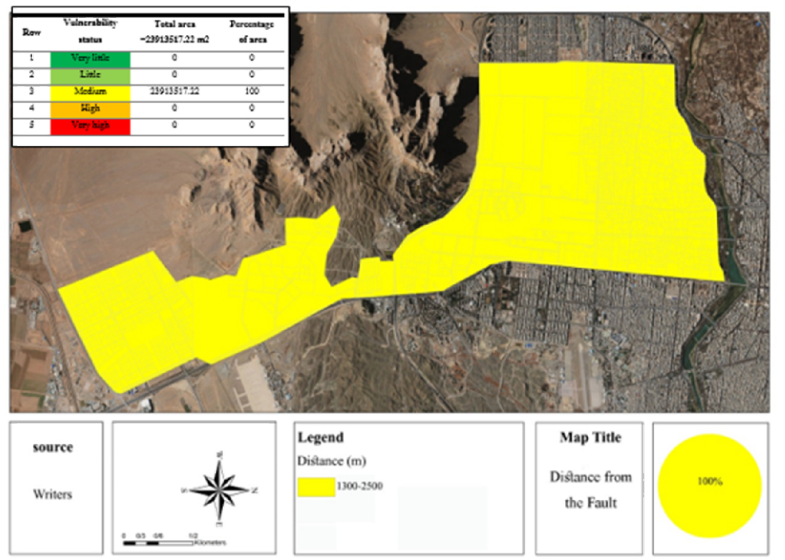

Figure 10. Map of distance from faults of district 5 of Isfahan in GIS
Iran, will be vulnerable to a possible earthquake due to the improper construction around faults, existence of some renovative and demolished buildings, use of unsuitable materials, small number of medical centers, looseness of the city soil, and unsuitable passages (28).

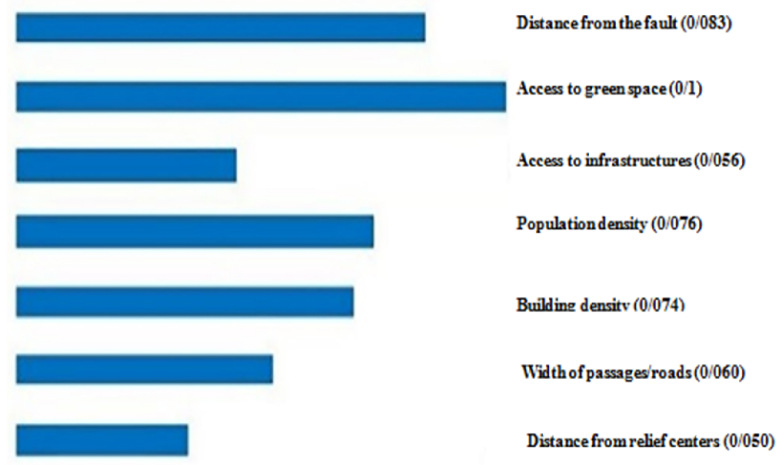

Figure 11. Weighting to indices

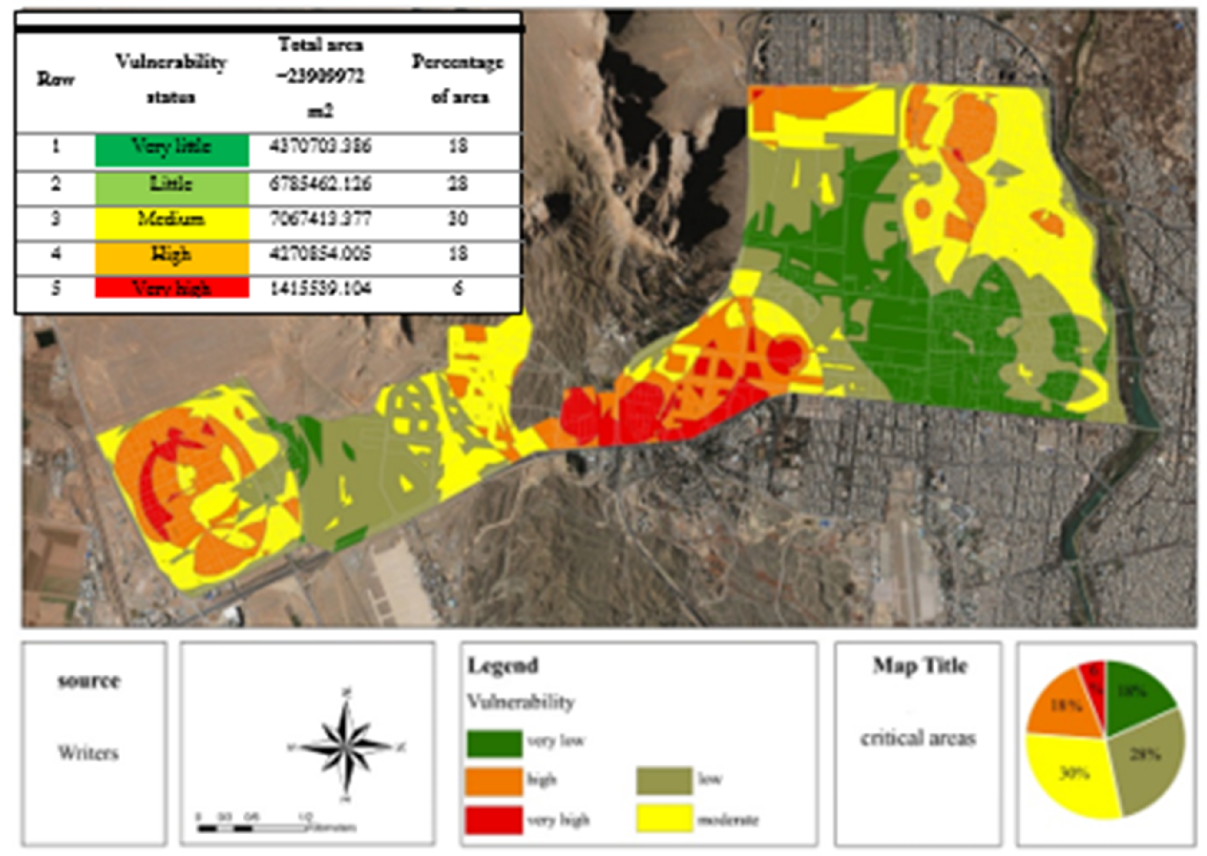

Figure 12. Map of critical areas of district 5 of Isfahan in GIS

\section{Discussion and Conclusion}

It is highly important to identify vulnerable areas and prioritize and properly plan for them before an earthquake occurrence. These measures allow rescue and relief operations to be carried out with better capacity and higher quality in the 
early hours of the disaster incidence. For this purpose, the indices of physical vulnerability (i.e., distance from the fault) and building and population density were used to assess the ability level to save people. Moreover, the index of access to passages and arteries and the indices of access to green space and distance from relief centers were used to assess transmission capacity and safe evacuation of individuals, respectively.

The value of the indices and the score of each for the preparation of the critical map were determined using the AHP method in Expert Choice software (version 11). Subsequently, to achieve the purpose of the research and determine the texture vulnerability of the region, the integration of space in the Geographic Information System was applied. Finally, the map of critical areas was prepared by overlaying the vulnerability maps of the area, standardizing them, and applying the weight of each. To this end, vulnerability layers of access to green spaces, population density, building density, width of passages, access to arteries and passages, and distance from the fault were used with coefficients of $0.1,0.076,0.074$, $0.60,0.050$, and 0.083 , respectively.

To determine the critical points, the results of investigating the vulnerability layers showed that $20 \%$ of the area lacked sufficient access to green space. The reason for the problem was attributed to the improper distribution of such spaces throughout the region, which leads to traveling longer distances during evacuating people and finding space for their initial accommodation. Therefore, it seems necessary to plan for the construction of more green spaces, especially in the middle and southern parts of this region. It was also found that $6 \%$ of the area had a high building density. Regarding this, monitoring new construction and not issuing more building permits can help the resilience of the area. Based on the results, $5 \%$ of the area lacked adequate access to relief centers, and increasing the number of these centers was highly important to transport injured people and accelerate rescue and relief operations.

\section{Acknowledgments}

None

\section{Conflict of Interests}

Authors have no conflict of interests.

\section{References}

1. Bartels SA, VanRooyen MJ. Medical complications associated with earthquakes. Lancet 2012; 379(9817): 748-57.

2. Muyser-Boucher I, Secula F. Shelter after disaster: strategies for transitional settlement and reconstruction. London: Department for International Development; 2010.

3. Dong L, Shan J. A comprehensive review of earthquake-induced building damage detection with remote sensing techniques. ISPRS J Photogrammetry Remote Sensing 2013; 84: 85-99.

4. Kial A, Aghili, M. Analysis and location of fire stations in Mashhad using AHP and GIS. National Conference on Spatial Information System (GIS), Tehran, Iran; 2009 [In Persian].

5. Hosseini G, Heidari HE. Measuring the resilience of historical sites against earthquakes and its upgrading (Case study: Sang-e Siah neighborhood of Shiraz). J Sustainable Architecture Urban Design 2018; 6(1): 89-103 [In Persian].

6. Zhang $\mathrm{W}, \mathrm{Xu} \mathrm{X}$, Chen $\mathrm{X}$. Social vulnerability assessment of earthquake disaster based on the catastrophe progression method: a Sichuan province case study. Int J Disast Risk Reduct 2017; 24:361-72.

7. Zangiabadi A, Mohammadi G, Safaei H, Gaedrahmati S. Vulnerability indicators assessment of urban housing against the earthquake Hazard case study: Isfahan housing. Geography Dev Iran J 2008; 6(12): 61-79 [In Persian].

8. Ghaed Rahmati S, Fazel S. Evaluation of urban safety area about the risk possibility of urban in habitats of Isfahan province. Geography Dev Iran J 2014; 12(36): 123-34 [In Persian].

9. Ganjeie S, Omidvar B, Fallah K, Rahimi Mamaghani M. Determining effective indicators in determining rescue and relief evacuation routes in urban areas from the perspective of crisis management. Second National Conference on Crisis Management: The Role of New Technologies in Reducing Vulnerability to Unexpected Disasters, Tehran, Iran; 2012 [In Persian].

10. Anari F, Eghbali N, Moayedfar R. Analysis and evaluation of effective variables on improving the urban road network resilience in the natural environment Man-made (case study: five areas of the eastern part of Tehran). Geography 2019; 9(3): 351-64 [In Persian].

11. Jafari EM, Arzegan M. A new model for location routing - relief logistic inventory in earthquake situations under fuzzy conditions based on risk management (Case study: Tehran city). Rahvar Sci Quart 2019; 28(8): 87-110 [In Persian].

12. Mohammadbeigi A, Mohammadsalehi N, Aligol M. Validity and reliability of the instruments and types of measurements in health applied researches. J Rafsanjan Univ Med Sci 2015; 13(12): 1153-70 
[In Persian].

13. Ülengin B, Ülengin F, Güvenç Ü. A multidimensional approach to urban quality of life: the case of Istanbul. Eur J Operat Res 2001; 130(2): 361-74.

14. Ahadnejad RM, Norozi MJ, Zolfi A, Jalili K. The assessment of urban social vulnerability to earthquake (A case study: Khoramdareh city). Geographical J Chashmandaz-e-Zagros 2011; 3(7): 81-98 [In Persian].

15. Saghaei M. Identification and prioritization of urban deteriorated texture in order to reduce the earthquake-induced vulnerability-case study: region 5 in Esfahan. Geographical Data 2018; 27(105): 171-82 [In Persian].

16. Dousti A. Earthquake vulnerability reduction of the historic fabrics of Jolfa Neighborhood. Reconstruction research department faculty of architecture and urban planning, Tehran. [Master Thesis]. Tehran: University of Tehran; 2016 [In Persian].

17. Hajinezhad A, Badali A, Aghaei V. The survey effective factors in vulnerability due earthquake in informal district of city zones with application of GIS: case study: 1 and 5 zones of Tabriz. J Natl Environ Hazards 2016; 4(6): 33-56 [In Persian].

18. Earthquake Vulnerability Reduction for Cities (EVRC-2). Bangkok, Thailand: Asian Disaster Preparedness Center; 2008.

19. Li S. The development of disaster prevention green space in China. Landscape Architecture Frontiers 2014; 2(4): 44-52.

20. Habibi K, Sheieh E, Torabi K. The role of physical planning in mitigating urban vulnerability against earthquake. Armanshahr J 2010; 2(3): 23-31 [In Persian].

21. Zangiabadi A, Rezaei M, Shahraki M, Mirzaei S. The evaluation and vulnerability analyzes of urban zone against the earthquake crises by using IHWP model case study: 3th zone of Isfahan city. Geographical Plan Space 2013; 3(8): 137-56 [In Persian].

22. Kazeminia A, Meimandi Parizi S. Evaluating the potency of city crossovers network with the approach of crisis managing by using GIS. J Geomatics Sci Technol 2017; 6(4): 87-106 [In Persian].

23. Soltani Fard H, Zanganeh A, Nodeh M, Hosseini F. Spatial analysis of the street network impacts on urban neighborhoods earthquake vulnerability. Case study: Amiriyeh neighborhood, Sabzevar. J Spatial Analysis Environ Hazards 2016; 3(1): 31-49 [In Persian].

24. Ebrahimzadeh I, Kashefidust DD, Hoseini A. Evaluating the vulnerability of urban regions against earthquake, case study: the city of Piranshahr. J Spatial Plan 2019; 5(1): 1-25 [In Persian].

25. Fu X. Planning and design of earthquake disaster relief corridor in stricken cities taking the design of the Yucheng district, Ya'an as application case. [Master Thesis]. Karlskrona, Sweden: Blekinge Institute of Technology; 2014.

26. Ali Asl Khiabani E, Sadeghi Niaraki A, Ghoddousi M. Relief routing after an earthquake (Case study: part of the district of Tehran city). Sci J Resc Reli 2018; 9(4): 1-17 [In Persian].

27. Fallahi A, Hassani A. Physical vulnerability assessment of the Hashtgerd new town against a probable earthquake. Geographical Res Quart J 2020; 35(4): 293-306.

28. Khodadadi F, Entezari M, Hassanpour F. Analysis of urban vulnerability to earthquake risk by ELECTRE FUZZY method (Case study: Karaj metropolis). J Appl Res Geographical Sci 2020; 20(56): 93-113 [In Persian]. 